\title{
Consideraciones sobre el sentido de un proyecto educativo en Contaduría Pública*
}

Considerations about the sense of an educational project in public accounting

Considérations sur le sens d'un projet éducatif en compatabilité publique

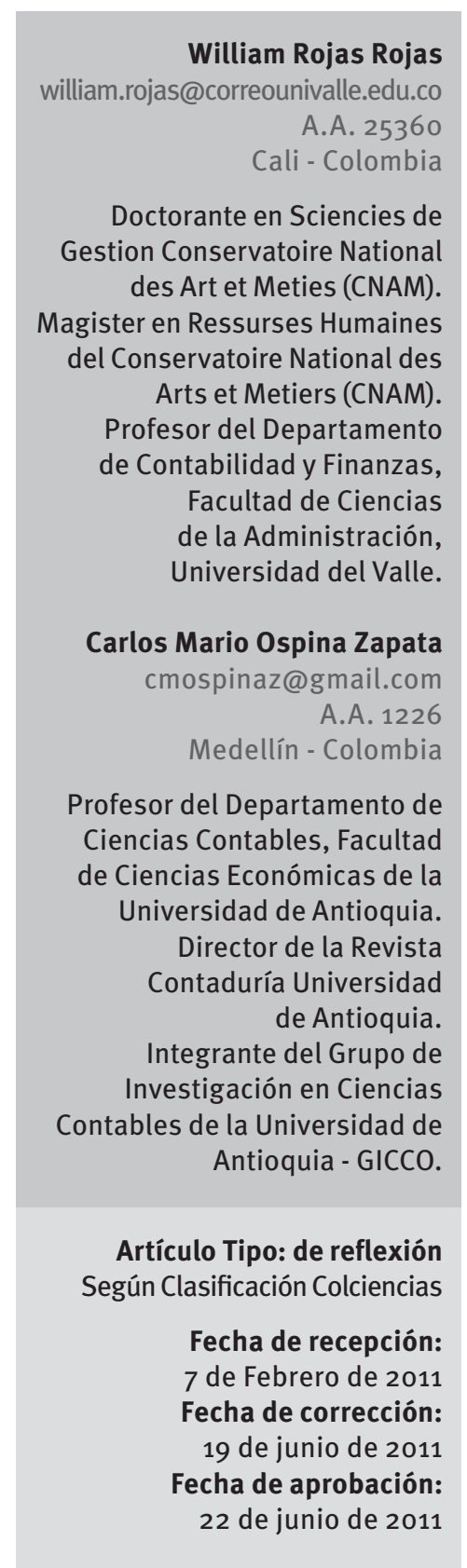

\section{Resumen}

El documento esboza cómo desde los Proyectos Educativos en Contaduría Pública, se hace necesario establecer los imaginarios y las estrategias que soportan las actividades pedagógicas orientadas a la construcción de una comunidad académica que entiende la necesidad de una formación política comprometida con el desarrollo de la individualidad y con los principales problemas de la sociedad. Señala que la concepción de la Contabilidad que soportaría la formación contable actual, debe superar la mirada reduccionista, técnica y mecanicista para dar paso a concepciones modernas, y en contextos de globalización, complejidad y sostenibilidad. Distingue que el propósito de formación que se concreta en las interacciones de la vida académica universitaria, se constituye en un dispositivo potente para que el estudiante aprenda a pensar dialéctica y significativamente la realidad de su tiempo (contexto político, social, cultural, económico). Por último, se esbozan sintéticamente algunos criterios como lo curricular, lo pedagógico, lo didáctico y lo evaluativo, como nociones fundamentales para lograr materializar un Proyecto Educativo en Contaduría Pública.

Palabras clave: proyecto educativo, formación, sujeto ético-político, contabilidad.

* Artículo de reflexión. Agradecemos a la Phd. Martha Peñaloza por las precisiones y el encanto que cultivó para pensar los proyectos educativos. Igualmente agradecemos los valiosos aportes de los árbitros anónimos para la cualificación del texto definitivo. 
Considerations about the sense of an educational project in public accounting

Consideraciones sobre el sentido de un proyecto educativo en Contaduría Pública

Considérations sur le sens d'un projet éducatif en compatabilité publique

\section{Considérations sur le sens d'un projet éducatif en compatabilité publique}

Consideraciones sobre el sentido de un proyecto educativo en Contaduría Pública

Considerations about the sense of an educational project in public accounting

\section{Abstract}

This document outlines how from the Educational Projects in Public Accounting, it is necessary to establish the iconographies and strategies which will support the pedagogical activities oriented towards the construction of an academic community which understands the need for a political formation engaged with the development of the individuality and with the main problems of the society. It points out that the conception of Accounting that will support the current accounting formation should look beyond the reductionist, technical and mechanist view, to give way to modern conceptions, in contexts of globalization complexity and sustainability. It distinguishes that the educational purpose concreted in the interactions of the college academic life, is constituted in a powerful education device which allows the student to learn to think dialectically and meaningfully the reality of their time (political, social, cultural, economic context). Finally, some criteria are succinctly outlined such as the curricular, pedagogical, didactic, evaluative criteria; notions that are foundational to materialize an Educational Project in Public Accounting.

Keywords: educational project, formation, ethical-political subject, accounting.

\section{Résumée}

Le document ébauche comment à partir des Projets Éducatifs en Comptabilité Publique, se fait nécessaire d'établir les imaginaires et les stratégies qui supportent les activités pédagogiques orientées vers la construction d'une communauté académique qui comprend le besoin d'une formation politique engagée avec le développement de l'individualité et avec les principaux problèmes de la société. Il signale que la conception de la comptabilité qui supporterait la formation comptable actuelle, doit aller au-delàs d'un regard réductionniste, technique et mécaniciste, pour faire place à des conceptions modernes, dans des contextes de globalisation, de complexité et de durabilité. Il distingue que le propos de formation qui se concrétise sur les interactions de la vie académique universitaire, constitue un puissant dispositif pour que l'étudiant apprenne à penser la réalité de son temps d'une façon dialectique et significative (contexte politique, social, culturel, économique). Finalement, cet article ébauche de manière synthétisée quelques critères comme celui traitant le curriculum, le pédagogique, le dialectique et l'évaluatif, en tant que notions fondamentales pour pouvoir matérialiser un Projet Éducatif en Comptabilité Publique.

Mots clef: projet éducatif, formation, sujet éthique. 


\section{Consideraciones sobre el sentido de un proyecto educativo en Contaduría Pública}

\author{
El hombre hace suyo un lugar no sólo con \\ el pico y la pala sino también con lo que \\ piensa al picar y palear.
}

Sandor Marai

\section{Introducción}

Existen muchos argumentos en pro y en contra de la actual dinámica en la que los programas de educación universitaria son sometidos al cumplimiento de normas que garantizan la calidad de su oferta. El cumplimiento de la normatividad tiene sentido si, en efecto, los programas se preocupan y se ocupan de los atributos que favorecen dicha calidad. Esta última no debe entenderse como la documentación de ciertos indicadores que expresan la sistematización de múltiples informes, sino como la acción sistemática y reflexiva sobre el deber ser de la educación, en este caso, la educación contable.

Para nadie es un descubrimiento que la universidad debe pensar al hombre, la sociedad y la ciencia en coherencia con un método y un marco referencial riguroso y específico. En el ámbito de la formación contable es menester disponer de importantes encuadres teóricos y arreglos metodológicos, consultivos del estado del arte de la disciplina contable, de los avances en las formas tecnológicas de manifestación de la contabilidad, de las relaciones contextuales e interdisciplinarias de la contabilidad, de las consecuencias éticas de la acción contable, además de una lectura juiciosa de los vínculos a establecer con lo pedagógico, lo curricular, lo didáctico, entre otros. Estas relaciones deben permitirle al profesional contable egresado de la universidad, proponer alternativas de comprensión y transformación de los problemas que facilitan el control organizacional e institucional.

La educación no debería verse como un proyecto empresarial cuya única finalidad sea arrojar una rentabilidad económica. La ciencia y todos los saberes desde tiempos inmemoriales, nunca han sido proyectados como empresas rentísticas. La universidad como institución social debe, ante todo, preocuparse por los desarrollos científicos y tecnológicos que garanticen que su entorno se desarrolle respetando la dignidad humana y la sostenibilidad del planeta. Resulta preocupante que la Universidad esté más interesada por las prácticas de gestión de la calidad sintonizadas con las lógicas de mercado, descuidando su misión natural cual es la búsqueda de conocimiento verdadero (Gracia, 2006), la puesta sistemática en crisis de los saberes acumulados y la construcción de nuevas posibilidades para la comprensión y la intervención de la realidad.

El Decreto 1295 de abril de 2010 reglamenta el registro calificado contemplado en la Ley 1188 de 2008 , y la oferta y desarrollo de programas académicos de educación superior. En especial, en el Capítulo II se establecen las condiciones para obtener el registro calificado.

Teniendo en cuenta esta reglamentación, hemos elaborado este texto que intenta avanzar en la comprensión de algunos aspectos que podría contener un Proyecto Educativo del Programa (PEP) de Contaduría Pública. Consideramos que este tipo de documentos facilitan el logro de importantes acuerdos interinstitucionales en relación con las filosofías en las que se deben asentar los programas de Contaduría.

Este texto no pretende agotar la discusión de la estructuración de los proyectos educativos en Contaduría Pública. Simplemente, intenta mostrar unas reflexiones articuladoras de un pensamiento, que cree en la posibilidad de encontrar un camino para la realización de acuerdos entre instituciones que tienen como política rectora el desarrollo de una educación contable comprometida con la libertad de pensamiento y sensible ante las exclusiones y estigmatizaciones de clase, género, etnia o religión (Nussbaum, 2010).

La metodología desarrollada para lograr esta síntesis se encuadra en una investigación documental en la cual los autores exploraron algunas de las fuentes más representativas en los campos de la educación contable y la contabilidad. Adicionalmente, las experiencias de los autores en los comités curriculares universitarios y la participación en procesos de transformación curricular son el caldo de cultivo en el que se alimentan las inquietudes más significativas 
frente al importante tema de la construcción de Proyectos Educativos en Contaduría Pública.

El documento está estructurado de la siguiente manera: en primera instancia se plantea un punto de vista sobre la comprensión de lo que es un PEP y sus relaciones con los proyectos institucionales; posteriormente se dedica un apartado a dilucidar la forma en que se entiende un Propósito de Formación que a juicio de los autores, no puede obviar, ni la descripción tanto del sujeto epistémico, ético y político que se desea formar, ni el contexto y/o entorno de formación que funda el proyecto. Seguidamente se consigna la perspectiva que sobre la Contabilidad sostenemos y la importancia de hacer tal demarcación para la construcción del Proyecto Educativo del Programa. Por último, se presentan algunas apreciaciones sobre conceptos tales como currículo, pedagogía, didáctica y evaluación. Con ello creemos aportar a la decantación de la estructura de un PEP y justificar la importancia de construir estos Proyectos Educativos en Contaduría bajo profundas dimensiones éticas.

\section{Demarcando. ¿Qué entender por un PEP?}

Un Proyecto Educativo debe presentar la filosofía que soporta el proceso formativo que se ha propuesto desarrollar una unidad académica, en este caso de Contaduría Pública. Así, un PEP debe explicitar, primero, las perspectivas tanto disciplinares como profesionales de la Contabilidad $^{1}$ en el marco de las misiones y las visiones de la Universidad y de la unidad académica en las que se inscribe el Programa; segundo, señala cómo el programa inserta la disciplina contable en los postulados morales y éticos que guían el camino planeado por la Universidad y, tercero, pone de manifiesto las concepciones relativas a los tópicos educacionales como lo curricular, lo pedagógico, lo didáctico, lo evaluativo, etc.

Lo anterior, deja claramente estipulado que un PEP de Contaduría Pública no debe plantearse sin presentar los argumentos que lo diferencian, por lo menos, de los otros programas académicos. A partir de mostrar la diferencia, o, si se quiere, la impronta del programa, se elabora el currículo, los perfiles profesionales y las estrategias pedagógicas que sustentan y justifican la existencia del mismo. Ateniéndose al espíritu de la normativa antes mencionada, todo PEP nace de un previo diagnóstico del estado del arte de la disciplina contable y de los campos de desarrollo profesional que se pretenden privilegiar para el contexto colombiano. Lo anterior, en la perspectiva de nutrir los enclaves de desarrollo profesional elegidos para cada programa académico.

En tal sentido, el diseño de un PEP debe precisar cómo cada programa de Contaduría Pública busca que sus estudiantes entiendan, y aprehendan los principios, valores, teorías y técnicas de las diferentes corrientes de la Contabilidad: principal, interpretativa y crítica (Chua, 1986/2009).

Así, todo PEP debe dejar claramente señalada la comprensión que tiene el programa académico de los problemas epistemológicos y metodológicos de la Contabilidad y del proyecto intelectual y ético, que se desea desplegar para estudiar y desarrollar el saber contable, lógicamente, en los límites de la formación de pregrado.

El PEP deberá dar cuenta de la forma como los estudiantes y los profesores harían distinciones y proyectarían tanto el saber como el instrumental contable. Como se sabe, los actos propios de la profesión contable en Colombia (enmarcados en la relación confianza pública y fe pública, entre otras) deben hacer prevalecer el empleo del juicio objetivo (imparcialidad), y la defensa del interés público, en el entendido de la información contable como re-presentación que afecta la comprensión de las realidades organizacionales.

\section{El PEP y los proyectos institucionales}

Un PEP de Contaduría Pública no puede plantearse por fuera de los principios y los valores definidos por la Universidad en la que él nace. Por eso, todo PEP debe mostrar cómo el programa forma y educa para impactar positivamente la sociedad en la que emerge.

Bajo esta perspectiva, todo PEP hace explícito el objetivo y la finalidad de su proyecto de forma-

1. La palabra Contabilidad, con la letra C mayúscula, indica que se hace referencia al término que da cuenta de las teorías, los enfoques, las técnicas y las anomalías del saber contable. Lo anterior se presenta así, para que el lector del documento considere que la palabra contabilidad no hace referencia a las acepciones del diccionario de la Real Academia de la Lengua que la definen figurativamente como: a) sistema adoptado para llevar la cuenta y razón en las oficinas públicas y particulares y b) aptitud de las cosas para poder reducirlas a cuenta o cálculo. 
ción (competencias) en términos del desarrollo ciudadano. Los programas de Contaduría Pública deben poner de manifiesto las pedagogías (dispositivos del, sobre qué y cómo se pretende educar y formar) que posibilitan que sus estudiantes comprendan que los procesos, los informes y los dictámenes contables, se han de elaborar siempre teniendo en cuenta los ideales y valores orientados al florecimiento de las democracias. Incluso, es un presupuesto ético para el proceso de formación de Contadores Públicos, advertir en qué sentido y en qué momentos históricos y contextuales la disciplina y profesión contable, han potenciado la emergencia de proyectos civilizatorios comprometidos con la inclusión social y el respeto del medio ambiente. La paz y la democracia son ideales inmanentes a la formación de profesionales privilegiados social y jurídicamente con la $\mathrm{Fe}$ Pública. Así, todo PEP debe argumentar cómo desde la formación se busca y se garantiza la defensa del interés público, el ejercicio de la civilidad digna y la defensa de los derechos humanos.

Un PEP de Contaduría Pública debe dar cuenta de las estrategias pedagógicas que garantizan que sus estudiantes están formados para respetar y hacer prevalecer el interés colectivo sobre el particular y promover la igualdad de oportunidades. Actualmente, el reto no está en mostrar las asignaturas que tienen por objetivo la "formación integral", sino en cómo cada programa consolida y materializa un currículo que articulado garantiza a lo largo de todo el proceso de formación, un referente tanto conceptual como moral para oponerse a los totalitarismos.

Manteniendo esta orientación, un PEP, simboliza los principios y los valores institucionales que garantizan que los profesionales pueden ejercer su saber bajo los presupuestos y los valores del pluralismo ideológico y la diversidad cultural. Un PEP instaura ante todo el marco filosófico que garantiza la autonomía y la universalidad de pensamiento que facultan el ejercicio de la autonomía moral que soporta el diálogo, la construcción crítica de la Contabilidad y su escenificación en el mundo del trabajo y de las organizaciones.

La búsqueda del desarrollo humano y la formación ideológica pluralista de las universidades, son, entonces, los soportes del Proyecto Educativo en Contaduría Pública. Consideramos que todo PEP debe dar cuenta desde sus ante- cedentes, la comprensión y justificación que la universidad tiene para ofertar el programa y las perspectivas que desde él se postulan para contribuir al desarrollo económico y cultural de su región.

Desde los PEP, un estudiante, un profesor o un ciudadano cualquiera, tendrá la oportunidad de hacer importantes distinciones sobre la orientación que los programas tienen de la Contabilidad y de la Contaduría Pública. Dicho de otra forma, un PEP debe mostrar con claridad el proyecto pedagógico que le asiste para formar profesionales éticos capaces de desempeñar su profesión en el marco de las relaciones interdisciplinarias de su saber con otros campos del saber (contabilidad-economía, contabilidadadministración, contabilidad-derecho, contabilidad-sociología, etc.). El PEP debe mostrar cómo y desde dónde un programa de Contaduría Pública analiza y pretende resolver problemas complejos de las realidades cotidianas de las organizaciones y las instituciones de su tiempo. Un PEP de Contaduría Pública es un plano referencial que articula una lectura de la sociedad y unos dispositivos de formación y gestión profesional que garantizan que el Contador Público puede contribuir al replanteamiento del status quo de su sociedad y de la comunidad contable de su tiempo. Con el PEP se debe mostrar la coherencia entre los objetivos del programa, el currículo y las estrategias pedagógicas y didácticas que soportan los planes de estudio.

Desde la perspectiva que alienta este trabajo, un PEP no puede ser un documento estandarizado sobre el ser y el hacer de la Contabilidad; el PEP es una urdimbre conceptual que demarca las bases comprensivas de la disciplina, de la profesión, y de la pedagogía con las que se cuenta para incidir en los sujetos comprometidos con su proceso de formación. Si el PEP no logra expresar esta urdimbre, es probable que la comunidad responsable de materializar tal proyecto deambule a la deriva y no tenga referentes desde los cuales evaluar lo correcto o por corregir en un proceso de formación de contadores públicos.

\section{Un propósito de formación (...)}

Se entiende como el marco referencial (conceptual) que permite interpretar y visualizar la presunción que tiene un programa académico de Contaduría Pública sobre la Contabilidad. En principio, este propósito da cuenta y 
Tabla No. 1. Algunas preguntas orientadoras - Definición de un propósito de formación para un

Proyecto Educativo en Contaduría Pública

$1 \quad$ ¿Es la Contabilidad un saber mono disciplinar o interdisciplinar?

$2 \quad$ ¿Cómo y de qué forma se produce "sentido" en Contabilidad?

3 ¿Cómo la Contabilidad produce, reproduce e interpreta las relaciones empresa-empresa, empresaEstado, empresa-sociedad?

$4 \quad$ ¿Cómo surgió y cuáles han sido los elementos contextuales que han hecho que la Contaduría Pública avance en su esencia profesional?

$5 \quad$ ¿Cómo y de qué forma se asumen las exigencias de la empresa y del mercado local y global?

6 ¿En qué sentido los contadores Públicos han acogido los desarrollos teóricos e instrumentales del derecho, de la economía, de las finanzas, del comportamiento organizacional?

$7 \quad$ ¿Qué relaciones y distancias pueden ser distinguidas en la tensión teoría y práctica en Contabilidad?

$8 \quad$ ¿En qué sentido el despliegue contable impacta el interés público?

9 ¿Qué discursos posiciona como legítimos la Contabilidad y su relación con otras disciplinas?

10 ¿Cómo opera la Contabilidad como parte de la tecno - estructura de las corporaciones?

11 ¿Cuáles arreglos tecnológicos se han producido y se producen para el despliegue de la profesión contable y cómo funcionan dichos arreglos tecnológicos?

12 ¿Cuáles regiones del discurso epistemológico de la ciencia han sido utilizadas para "apreciar" la Contabilidad?

13 ¿Se debe la Contabilidad en sus manifestaciones a tensiones de orden ideológico - político económico?

14 ¿Cuál Contabilidad para qué sociedad?³

15 ¿Qué implicancia tienen las ciencias humanas y sociales en la re-visión de la Contabilidad?

Fuente: elaboración propia.

explica la forma en que se piensa y se proyecta el saber contable y la Contaduría Pública². Así, el propósito de formación encuadra y da sentido al enunciar aquello que el programa asume como perspectivas del desarrollo y del conocimiento contable. Un conjunto de preguntas y sus respuestas sirven para tejer y construir el propósito de formación de un programa (ver tabla No. 1). Las comunidades académicas de los programas estudian y deliberan, debaten las respuestas a estas preguntas y construyen consensos.

El propósito de formación muestra entonces la estructura conceptual de una demarcación, que se presenta como un "relato" institucional (construido intersubjetivamente) respecto del desarrollo y la evolución del saber contable. El anterior planteo, indica que el propósito de

2. No debe confundirse el sentido que aquí desarrollamos de la idea de propósito de formación con objetivo de formación, como enunciado que expresa un logro parcial y concreto que debe alcanzar el estudiante en su proceso educacional. Aquí desarrollamos una noción más abarcativa como puede colegirse de la lectura de este apartado.

3. Aquí nos inspiramos un poco en la pregunta pertinente que hace y desarrolla el profesor Rubén Jaramillo Vélez: ¿Qué universidad para qué sociedad? Vale la pena observar el texto de este filósofo colombiano intitulado "Colombia la modernidad postergada", en especial para interpretar cómo en nuestra sociedad se transita de un institucionalismo católico a la anomia social, sin haber vivido un proceso de secularización. Y esto nos parece importante porque la Universidad al no tener presente con rigurosidad el tipo de hombre y sociedad que quiere y el tipo de rupturas que debe establecer con los sistemas de pensamiento precedentes, deja sin referentes y, por ende, sin posibilidad de coherencia, las tentativas de formación vigentes. Por ello los programas deben posicionar estas preguntas por el tipo de sociedad y de hombre que necesita un proyecto de nación específico. Creemos que el PEP es uno de los lugares para expresar con total radicalidad este tipo de concepciones. 
formación entrega los mínimos para reconocer aquellos conceptos y teorías que se descartan, aquellos conceptos y teorías que se asumen y se proyectan para consolidar el saber y la profesión contable, desde una manera de pensar que defiende y promueve una moral de actuación institucional.

Sin pretender defender el imaginario de la coherencia, consideramos, que todo propósito de formación apunta a salvaguardar una forma de creación y un juego de tensiones propias de una comunidad que pretende crear conocimiento bajo una identidad estética que se respalda per se en una lógica de producción del conocimiento institucional.

\subsection{El sujeto epistémico, ético y político que se desea formar}

Todo propósito de formación debe entonces dejar claramente estipulado el sujeto epistémico, ético y político que se desea formar. Con ello, el PEP enriquece las discusiones y las reflexiones sobre la dimensión social de la Contabilidad y la apuesta que se hace desde las universidades por contribuir al proceso material y cultural de las múltiples identidades de América Latina. Especificar los marcos epistémicos, éticos y políticos permite esclarecer cómo un estudiante puede ingresar y, por supuesto, desprenderse críticamente de las verdades que le sujetan al conocimiento de su época.

Sobre los orígenes y los caminos de evolución de la naturaleza, la cultura y el hombre, se han tejido diferentes relatos que trabajan sobre vías de desarrollo diferentes. Por tanto, todo propósito de formación debe panorámicamente, dejar claramente estipulada la asunción que se tiene de lo que Jean Francois Lyotard llama los relatos de la emancipación ${ }^{4}$ que legitiman instituciones, prácticas sociales y políticas, éticas, formas de pensar, simbolismos, etc. (2008, p. 61)

Debemos ser conscientes que todo programa busca que sus estudiantes y egresados se "formen" (acción de darse forma); para ello tomarán como materias primas o puntos de partida, las concepciones y complejidades que del saber y la profesión contable se promuevan. Es indudable que el proyecto educativo que se concreta en las interacciones de la vida académica universitaria, se constituye en el dispositivo que procura que el estudiante aprenda a pensar dialéctica y significativamente la realidad de su tiempo (contexto político, social, cultural, económico).

\section{Tabla No. 2. Algunas preguntas orientadoras - Formulación de las características de un sujeto}

ético - político en la construcción de un Proyecto Educativo en Contaduría Pública

$1 \quad$ ¿Cómo y desde que idea de hombre se asume que la Contabilidad es una disciplina social?

$2 \quad ¿ C u a ́ l e s$ son los diferentes marcos conceptuales que se requieren para representar y proyectar los escenarios económico-financieros en los que opera la Contaduría Pública?

3 ¿Cuáles son los marcos contextuales que se plantea el programa para que los estudiantes comprendan las racionalidades empresariales y estatales propias del Occidente y el Oriente contemporáneos?

4 ¿Qué caracteriza y cómo ha devenido el conjunto de las mentalidades y las racionalidades de América Latina?

5 ¿Cómo entender la racionalidad del hombre que ejercita la Contaduría Pública?

$6 \quad$ ¿Cuáles son los referentes que permiten creer en la capacidad problematizadora del ser humano?

$7 \quad$ ¿Qué sentidos de las tensiones correcto - incorrecto, bueno - malo, justo - injusto, admisible inadmisible sientan las bases para el juicio y la acción ética del contador público?

$8 \quad$ En qué sentido las humanidades y la problematización de lo humano e inhumano favorecen la formación de una subjetividad del Contador que le permita interactuar con solvencia moral en las diferentes formas del mundo de la vida? 
Al igual que para la descripción de un propósito de formación, se considera válido señalar que en la formulación del sujeto ético-político se deben consensuar respuestas a importantes interrogantes que a su vez coadyuvan en la consolidación de la misión y visión de los programas de Contaduría Pública (Ver tabla No. 2).

Creemos que el propósito de formación de un programa de Contaduría Pública, en síntesis, está orientado a evitar que sus participantes queden atrapados en marcos teóricos e ideológicos que les impidan participar críticamente en la construcción de su saber, de su profesión y de su sociedad. Con su enunciación y escenificación en la vida formativa se configura la condición de sujeto epistémico, ético y político.

\subsection{Contexto y/o entorno de formación}

Todo propósito de formación debe pensar la complejidad de su presente. El actual fenómeno globalizador obliga a que los programas de estudio relacionados con el fenómeno económico piensen la globalización. Así, todo programa debería mostrar cómo asume la globalización, puesto que, traspasa el territorio y obliga al cuidado de las formas y las representaciones que instauran y desarrollan las identidades.

Al decantarse la forma en que el programa problematiza el hecho "globalización", se logra elucidar la forma en que se justifica la preservación de las culturas locales y humanas contemporáneas. La globalización exige unas formas de potenciación de las libertades ideológicas de los individuos y los colectivos económicos. El fenómeno global contemporáneo da pie para que todos los proyectos educativos busquen nuevas formas de actuar que garanticen la vida digna y el mantenimiento del planeta.

Desde esta lectura, el propósito de formación de un programa de Contaduría Pública entiende la globalización contemporánea como todos los procesos socio-culturales dominantes que obligan a que los profesionales actúen bajo asociaciones conceptuales y redes de interpretación (económicas, legales, sociales, políticas y/o culturales) que ayuden a trascender los problemas de información contable- financiera-social de las organizaciones contemporáneas en sintonía con los imaginarios simbólicos que han dado, y dan, identidad territorial.

Precisar el contexto y/o entorno de formación contribuye a demarcar la perspectiva interdisciplinaria o transdisciplinaria que le asiste al campo contable. Forjar un pensamiento epistémico sentipensante ${ }^{5}$ en los estudiantes y profesores de Contabilidad requiere de una lectura que comprenda la forma en que se universalizan las prácticas y los ideales en lo contemporáneo.

El que la globalización económica actual requiera de unos marcos de comparación de la información contable-financiera, implica para el programa, la necesidad de presentarles a los estudiantes la posibilidad de formarse para potenciar las identidades y las necesidades locales en el juego de las pretensiones geopolíticas y económicas expansionistas.

Por lo anterior, la globalización y los fenómenos globalizadores se convierten en planos contextualizadores que pueden ayudar a transversar las diferentes perspectivas y enfoques de la Contabilidad.

El sujeto epistémico (profesional) se perfila y se estructura desde un currículo que busca formar para que los participantes del programa de Contaduría Pública estén en la posibilidad de entender los imaginarios simbólicos que permean el pensar-vivir de la época, claro está, dejando espacios para que puedan construir pensamiento diferente a favor del fortalecimiento de los "paradigmas" que convergen en el saber contable.

\section{La contabilidad. perspectiva de cara a un PEP}

El PEP contiene una declaración sintética de los sentidos más contundentes que se atribuyen a la disciplina contable y a la profesión de la Contaduría Pública. La comunidad que está pensando el proyecto formativo estudia y construye consensos sobre la perspectiva más congruente con las pretensiones educativas, competencias, y procesos de relacionamiento social presupues-

5. Concepto que expresa la relación que debe existir entre razón y amor, entre las cosas de la cabeza y las cosas del corazón, entre esa estructura del saber en su sentido más clásico, y la sensación; estas relaciones instalan una forma de la verdad más armónica. Cuenta Fals Borda que esta idea no es propiamente su construcción, sino que está presente en la forma en que viven y asumen su existencia los integrantes de las culturas ribereñas del río Grande de la Magdalena en Colombia. (Fals Borda, 2009. Presentación de Víctor Manuel Moncayo). 
tados para el ejercicio de un profesional contable en el mundo de las organizaciones y en el mundo de la vida.

Sin embargo, aunque esto suena demasiado flexible, nos preguntamos lo siguiente: ¿es posible concebir que en la actualidad un programa de Contaduría Pública pueda justificarse desde el prisma que observa la Contabilidad como mero reservorio de instrumentalidades, aséptico y objetivo, en el plano registral y de producción de información útil para la toma de decisiones? ¿es posible justificar un proyecto de formación en Contabilidad centrado en la operación de tecnología transferida bajo la metodología de copia difusión (Gómez y Ospina, 2009), sin potenciar en el estudiante unos elementos conceptuales para contextualizar el saber contable y reconocer los intereses inmanentes al mundo del trabajo contemporáneo? Nos resistimos a los programas que se proyectan como espacios de disciplinamiento profesional de la Contaduría Pública, puesto que advertimos que esta orientación es contraria al sentido de Universidad. La Universidad es un espacio para construir pensamiento, para la fabricación de lógicas, para la crítica (puesta en crisis) de los saberes acumulados, para la innovación, para la ética de la relación entre conocimiento y necesidades sociales, para la plenipotencia de sujetos comprometidos con una sociedad más justa e incluyente. La contabilidad vista como instrumentalidad se aleja de estos sentidos descritos para la Universidad. Por lo anterior, tomamos distancia de aquellos que consideran admisible construir un PEP que representa la Contabilidad como una mera técnica operable, como una legalidad en tanto acervo probatorio, o como un medio irremediablemente necesario para la fiscalidad de las organizaciones.

Entendemos por Contabilidad algo sustancialmente más complejo, un campo del saber que involucra diversas manifestaciones de las tensiones teoría - práctica, hecho - valor, saber - interés, verdad - poder, local - global, ciencia - tecnología, legalidad - legitimidad, disciplina - interdisciplina, entre otras. En la formación de contadores públicos la universidad y su programa de Contaduría están en el deber de demarcar estas tensiones y señalar sus consecuencias, decantando las condicionantes históricas, contextuales, éticas, y potencialidades que las definen. En este sentido, la formación contable se ha ido alejando de aquellas tradiciones que creían que el centro pedagógico de la Contabilidad giraba alrededor de operaciones maquinales y rutinarias de las organizaciones. La enseñanza contemporánea de la Contabilidad se encuentra cimentada en un proceso epistemológico riguroso que responde a las tensiones mencionadas y sus implicaciones en el hacer. Y, por supuesto, esa formación le permitirá al profesional contable ejercer sus campos de acción de forma consciente y crítica, que en ningún caso significa, con debilidades técnicas o prácticas.

Por lo tanto, el PEP deja explícita la concepción de la Contabilidad desde la cual se inspira el propósito de formación. Y la comunidad académica del programa adquiere el compromiso de mantener la discusión sobre la validez, actualidad, pertinencia y congruencia de dicha concepción en relación con el momento histórico y contextual de la disciplina y con la prospectiva de la profesión contable en una sociedad global y con aspiraciones de justicia y equidad social.

Para dar un ejemplo, los autores aceptamos la idea que los Proyectos Educativos en Contaduría Pública tienen profundas consecuencias en la forma como los actores/agentes, entienden, interpretan, problematizan y actúan para la co-producción del actuar organizacional contemporáneo. Es indudable que la formación contable provee una cierta racionalidad que le permite a los contadores públicos hacer distinciones, por ejemplo, sobre lo que es y no es un activo: un edificio, un terreno, una inversión o un inventario, etc. Las distinciones conceptuales y las definiciones se hacen y/o aceptan sobre la base de encuadres nocionales que se relacionan con el enfoque teórico y técnico dominante. Por lo anterior, se acepta que la Contabilidad no es pasiva en la formación de un determinado orden social. Ella provee todo un poder de síntesis y abstracción, que llevado a los proyectos educativos puede ponerse a favor de la comprensión y la problematización de los sistemas de relevancias que soportan un determinado status quo.

Un PEP no debería asumir la realidad del sistema conceptual del capitalismo como un artificio natural, puesto que éste obedece $a$ un conjunto de detonantes de orden sociológico, de relacionamiento de saberes y prácticas, y de entrecruces ideológicos. La idea de que algunas manifestaciones en vigencia de la Contabilidad en concomitancia con otros saberes y prácticas sociales, ha prefigurado la escena del "hombre gobernable" (Miller y O'Leary, 1987/2009), o la expresión de que la Contabilidad tiene poder constitutivo sobre la realidad (Larrinaga y $\mathrm{Ca}$ - 
rrasco, 1996), dan cuenta del profundo impacto de esta disciplina en el orden instituido de las organizaciones y de los valores sociales vinculados a la racionalidad económica contemporánea; ya desde hace varias décadas el profesor Mattessich (2002), la definía como un modo de pensar respecto de los atributos crematísticos relacionados con la competencia en la obtención de la ganancia.

La Contabilidad no debería ser asumida como un mero sistema de información contable, mucho menos como el proceso que se sigue para el registro contable y la confección de estados o informes. Sobre esto ya son varios los teóricos de la contabilidad que nos hacen advertencias respecto de la debilidad que tal postura implica para la formación del contable. Los arreglos teóricos que se han producido en el devenir de las comunidades académicas contables y sus dialécticas con las prácticas profesionales, explican la evolución epistémica y praxeológica de la Contabilidad; incluso, desde la consideración de estos debates y su relación con el problema de la regulación contable, podemos construir la arquitectura axiológica por la que ha transitado la Contabilidad. Es evidente, entonces, como la Contabilidad resulta fundacional para mantener la racionalidad actual con la que opera el sistema económico, soslayándose así, la tradicional idea de la Contabilidad como representación, como imagen isomórfica o fotografía de la realidad organizacional. La Contabilidad construye una visión de la organización económica que es avalada implícitamente por la sociedad, justamente porque proviene de la Contabilidad. Esta es una de las paradojas que debe ser deconstruida en el proceso de la formación contable.

Si observamos la siguiente definición del profesor Jorge Manuel Gil, podemos dimensionar la gran responsabilidad que tienen los programas de Contaduría Pública en el desenmarañar, diseccionar, distinguir, los elementos que hacen de la Contabilidad una disciplina y manifestación social de alta complejidad:

La hipótesis es que la Contabilidad produce y presenta unos productos finales como información factible de ser interpretada. La taxonomía de estos productos es a partir de modelos de dimensiones económicas (las relativas al proceso de acumulación de las organizaciones), financieras (referidas a las cuestiones monetarias en un sentido amplio) y patrimoniales (como estructura de derechos de propiedad y control, activos y pasivos) de la realidad, y esta representación se muestra con un lenguaje especializado que permite una estructura de datos (cualitativos y cuantitativos) interrelacionados que, si se utilizan, se convierten en información y que, al ser analizados e interpretados, se transforman en conocimiento de la realidad (Archel, Husillos, Gil y Rojas, 2009, p.63).

Como puede verse, en la hipótesis anterior parece obvio que la Contabilidad se configura bajo diversos sistemas interdisciplinares que se relacionan con el currículo: la economía, el derecho, el comportamiento organizacional, la teoría del conocimiento, la lingüística, las finanzas, la matemáticas, entre otros. Dichas disciplinas sociales y/o humanas tienen su propia historicidad y contextualidad $y$, por ende, se encuentran abocadas a programas de investigación en competencia (acuerdos y polémicas internas). Así, la Contabilidad que se divulga desde y en los programas de estudio, no debería asumirse bajo la pretensión de que ella se forma e instaura en marcos conceptuales no problemáticos. Pensemos de nuevo en la veracidad del siguiente planteamiento: "cuando enseñamos Contabilidad estamos abordando una realidad multidimensional cuya representación se concreta deconstruyendo y reconstruyendo conocimientos que reconocen múltiples orígenes" (Archel y otros, 2009, p.68), ¿será que al formular los PEP hoy, se puede considerar fútil este planteamiento?

Por ejemplo, quienes asumen la Contabilidad como una disciplina emergente hermana del derecho, deberían desde su proyecto educativo contraer la responsabilidad de formar al estudiante al menos en las siguientes distinciones: a) los procesos de consolidación y aplicación de los estándares contables (que desde su emergencia se relacionan con ideologías propias del imaginario político); b) en la diferenciación entre convenciones y características económicas de la contabilidad (Sunder, 1997/2005), c) las consecuencias socio-económicas de las reglas contables, y los procesos de negociación o dominación política en la promulgación de dichos estándares.

Para el caso específico de la Contabilidad Financiera o de algunas manifestaciones de la Contabilidad de Gestión, consideramos que un programa debe mostrar desde su PEP cómo 
éstas son problematizadas por la comunidad académica. El ya citado profesor Gil, nos resulta nuevamente útil para justificar nuestros planteamientos. Gil sostiene que bajo la enseñanza de la Contabilidad Financiera, hay una abundancia de parcializaciones de profesores que:

* "Enseñan teorías en uso conservadoras y basadas en la repetición de diseños, sin relacionar el modelo con la estructura metodológica de la contabilidad (por ejemplo, se enseña el concepto de "beneficio líquido y realizado", sin involucrarlo con la "creación de valor" y su distribución y sin referenciarlo con la estructura socioeconómica que lo valida);

* educan sobre los modelos económicos del pensamiento único, sin avanzar sobre los funcionamientos sistémicos y la crítica construccionista del modo de producción capitalista (se enseña "patrimonio" como "propiedad", sin analizar la evolución sistémica de "control"; se enseña la "consolidación de los estados financieros" sin relacionarlos como el proceso de la concentración de la riqueza);

* presentan argumentos de administración exitosos, sin analizar el rol de la empresa concreta como organizadora de la producción (ej., la contabilidad de costos ABC se desentiende de los requerimientos de la eficiencia social de las organizaciones); no relacionan el conocimiento elaborado con las acciones concretas de agentes económicos con lo que limitan la aplicabilidad de la contabilidad (por ejemplo, desconocen que la cifra de negocios -"ventas"- puede ser determinante del valor de mercado de la empresa." (Archel, y otros, 2009, p.70).

Creemos que en el diseño de los PEP es menester promover una concepción de la disciplina contable como un campo del conocimiento con tradición de investigación plural y global, con múltiples corrientes y enfoques (Larrinaga, 1999, Chua, 1986/2009, Gómez y Ospina, 2009). La disciplina contable se ha desarrollado al amparo de los conocimientos y los métodos científicotecnológicos modernos. Así, las concepciones sobre el objeto de estudio y el método en Contabilidad se han enriquecido por las miradas más funcionalistas, positivistas y objetivistas del conocimiento. Apropiándose de las perspectivas, construccionistas, hermenéuticas e intersubjetivistas, la Contabilidad ha emergido como un saber estratégico para el re-direccionamiento de las sociedades y las culturas. La educación contable está convocada a formar a sus estudiantes en la capacidad de reconocer estas tradiciones, identificando sus alcances, sus empatías teóricas, sus posibilidades y sus limitaciones, sus capacidades explicativas, sus concepciones de la realidad, del conocimiento y de la sociedad, sus impactos en la comprensión del mundo de las organizaciones, la racionalidad económica, y la tecnología contable, y su potencial aplicabilidad.

\section{En palabras de Gómez y Ospina:}

la Contabilidad no solamente actúa como medio, sino que se constituye en un conocimiento que amplifica, modifica, re-contextualiza y determina ideas, prácticas institucionales, estructuras simbólicas y morales, e intereses y visiones del mundo. Con ello la Contabilidad se descentra de la perspectiva que la concibe como un conjunto de técnicas neutrales, brotadas de una lógica "pura”, prohijada por el interés individual, racional y maximizador (2009, p.14-15).

La Contabilidad concebida como disciplina (saber metódico, sistémico, crítico) es la base de una profesión contable más compleja y con mejores impactos en las intervenciones organizacionales que despliega. La Contabilidad concebida sólo como técnica resulta, entonces, la base de una profesión con un papel menos contundente en la comprensión de los grandes problemas de la socio-economía contemporánea.

De modo que el PEP instaura como eje filosófico de la enseñanza y de la investigación (desde el horizonte de la concepción que hemos puesto en consideración) el que la Contaduría Pública es un campo de acción profesional que sólo se dignifica cuando se consultan y se ponen en escena los elementos que han prefigurado la arquitectura actual de la Contabilidad, cuando se evalúan esos elementos con las herramientas que provee el método científico (en un sentido amplio que vincula los modernos arreglos de las ciencias sociales), cuando ponemos en diálogo esa estructura construida histórica y humanamente con los fines y las necesidades de trascendencia de la sociedad actual, y cuando podemos prever la construcción de un juicio sentipensante para los actos de transformación de las maneras de intervención que utilizamos desde la Contabilidad en 
el mundo de las organizaciones e instituciones contemporáneas.

La Contaduría como profesión refleja y debe reflejar un ethos y una moral universal que permita el desarrollo de las identidades personales y culturales existentes en la sociedad globalizada de nuestro tiempo. En nuestro entender, el programa académico de Contaduría puede ser pensado como un espacio formativo que busca cultivar en sus participantes una ética y un espíritu crítico que les permita entender que la praxis contable exige una autonomía moral para actuar "conscientemente" en la producción de información, evaluación, y atestación de las actividades económicas y/o sociales que sean objeto de distinción por parte de la Contabilidad.

Ser y hacerse Contador Público implica elegir una perspectiva ética que le permita al profesional enfrentar diferentes lógicas y simbologías culturales que se inscriben en ideologías sobre la naturaleza, la vida, las personas y el uso de la ciencia y la tecnología. El PEP, entonces, deberá explicitar la Contabilidad concebida por el programa, como constructo que guía la comunidad académica y favorece la evaluación de la consecución del propósito de formación relatado. Insistimos: hoy por hoy, no tiene sentido un PEP que ve la Contabilidad como mera instrumentalidad inofensiva e incapaz de articularse a las lógicas de cambio social que urgen para asir una existencia digna, incluyente y fraterna.

\section{Las nociones de currículo, pedagogía, didáctica y evaluación en el texto del PEP}

En el PEP se consigna el conjunto de referencias y soportes que permite materializar el propósito de formación. Como es lógico, ello comporta poder concretar en el espacio de lo educativo, el logro de la concepción consensuada de la Contabilidad y del sujeto epistémico, ético, estético y político que le resulta coherente. Es en la articulación de los grandes conceptos educativos como el currículo, la pedagogía, la didáctica, la evaluación, la gestión, entre otros, que dejamos pistas de cómo es que vamos a formar, de qué nos vamos a valer y con qué sentidos podemos lograr lo proyectado para darle atributos a un profesional de la Contaduría Pública.

La comunidad académica responsable del proyecto educativo, y luego de hacer un estudio profuso de los conceptos educativos enunciados, procederá a consensuar la tipología que será su guía en la formación.

El currículo es la estructura. El currículo permite disponer y articular, materializar, vía asuntos concretos, tales como, problemas de formación, áreas, campos, temas, subtemas, tiempos, espacios, documentos, enfoques, guías, planes de estudios, secuencias, productos, núcleos, gestiones, perfiles, organigramas, normogramas, reglamentaciones, estrategias, etc. Lo curricular debe obedecer ciertos principios, como la pertinencia, la flexibilidad, la integralidad, la interdisciplinariedad, la eticidad. Como puede observarse lo curricular trasciende con creces uno de sus productos: el plan de estudios. En el PEP se deben consignar estos arreglos que dan forma al currículo.

Siendo coherentes con lo expuesto desde nuestra concepción de la Contabilidad, y en sintonía con lo planteado por Barragán, es preciso superar la perspectiva de muchas universidades que ofertan el programa de Contaduría Pública donde "el currículum se ha visto desde una óptica pragmática, en torno a organizar 'qué' y 'cómo' enseñar reduciendo problemas centrales del proceso de formación a una organización técnica" (2008, p.162).

La pedagogía busca en la filosofía de la educación respuestas a preguntas relacionadas con la esencia del ser humano (Díaz y Quiroz, 2001). La pedagogía estudia, devela, las ideas de hombre y de sociedad que han gravitado en diferentes períodos históricos y en variados contextos en los procesos educativos. Por ello, cuando preguntamos por la pedagogía en una propuesta de formación, preguntamos por el tipo de ser y de relacionamiento social que es prohijado por la materialización de dicho sentido pedagógico. Los posibles horizontes en este ideal dan origen a los modelos pedagógicos. Según Flórez (1989) citado por Díaz y Quiroz (2001) éstos, más que describir y penetrar en la esencia misma de la enseñanza, "reglamentan y normalizan el proceso educativo definiendo ante todo qué se debería enseñar, a quiénes, con qué procedimiento (...) para moldear ciertas cualidades de los alumnos". "El modelo pedagógico representa el ideal de hombre y de mujer que se proyecta para un contexto histórico, social y cultural determinado, en coherencia con un ideal de hombre y de mujer proyectado para el contexto universal" (P.122). 
El PEP deberá indicar la comprensión que sobre lo pedagógico se asume como plataforma del programa. Conocemos que existen modelos pedagógicos tradicionales que responden a proyectos educativos otrora emprendidos. También evidenciamos, que pese a los cambios actuales y a las necesidades sociales, muchos programas persisten, consciente o inconscientemente, en mantener propuestas pedagógicas que claramente resultan disonantes, por cuanto subrayan la formación funcional, acrítica, mecanicista, memorística, y enciclopédica. Otras propuestas se abren paso, nuevos enfoques alternativos, modelos pedagógicos desarrollistas o sociales que parten de enfoques constructivistas, con una concepción del aprendizaje más participativa y significativa, que le permite al sujeto posicionarse en su sistema mundo e incluso propulsar su emancipación.

El asunto no es entonces asumir uno u otro modelo pedagógico de forma meramente enunciativa. Ya sabemos que los PEP o los documentos rectores pueden consignar cualquier cantidad de cosas que no hacen parte de la cotidianidad de los programas. Lo importante es que la comunidad académica comprenda las consecuencias reales para la formación de la asunción de una postura pedagógica, de un sentido de lo pedagógico, escudriñando con hondura los atributos y las limitaciones en pro de cimentar la acción educativa. Una tarea rigurosa en este sentido mostrará en el mejor de los casos, que no se trata de escoger un modelo pedagógico sino de proponer uno que resulte del esclarecimiento del tipo de hombre y de mujer, y de sociedad al que le apuesta el programa de Contaduría Pública en oferta. Y dicho modelo (guía), puede ser una mixtura de los atributos más relevantes de los modelos pedagógicos entrevistos por la disciplina de la pedagogía. De cualquier forma no podemos perder de vista que "el par formación-pedagogía tiene que habilitar al sujeto para enfrentar un mundo simbólicamente sedimentado, mediado comunicacionalmente, en el que cada quien tiene la tarea de ser sujeto, en que cada quien tiene la tarea de ser persona" (Vargas, 2000, p.61).

Por otro lado, el PEP integra una idea de la didáctica general que resulta coherente con los presupuestos pedagógicos consensuados. Sin embargo, debe quedar claro, que en lo relacionado con la formación, la didáctica es análoga a la metodología cuando hablamos de investigación: la metodología se define atendiendo a las características del objeto de estudio. De igual forma, la didáctica se construye en atención a las características de los objetos de formación, de los problemas y campos del conocimiento; es por esto que podemos hablar de didácticas específicas o de didaxis por áreas del conocimiento. Nuestra idea es que lo didáctico ha de ser un campo de reflexión permanente por parte del docente y de la comunidad académica del programa, y en atención a las características de los espacios para la formación. Vale decir que no entendemos didáctica como medios de apoyo para la clase, ni como logística del proceso de enseñanza-aprendizaje. Nos llama la atención una comprensión de la didáctica como "medianía, ella misma no es un centro, pero centraliza la distribución de formas discursivas-narrativas, en cierto modo, ella es como una suerte de ducto para que de uno a otro los interlocutores 'jueguen' y, en ese proceso, intercambien sentidos, interactúen". (Vargas, 2000, p.62). En el espacio de la didáctica el docente debe hacerse preguntas constantemente sobre su papel en el proceso de de enseñanza - aprendizaje. Su preocupación fundamental ha de ser "la de preparar a sus alumnos para que cuando desaparezca su relación con ellos, puedan continuar su formación por sí mismos. Su identidad y capacidad para enfrentarse a nuevos problemas será el mejor legado del orientador" (Cardona y Zapata, 2006, p.48).

Y por último, que no quiere decir agotamiento de lo posible como contenido del PEP, es necesario incorporar la reflexión sobre el proceso evaluativo en sentido amplio, vinculando tanto la evaluación curricular, la evaluación profesoral, la evaluación de la gestión, como la evaluación de aprendizajes dirigida a los sujetos en formación. La evaluación hace parte del proceso que permite lograr el propósito de formación. Para ello se deben institucionalizar los grupos, comités, mecanismos e instrumentos que permiten señalizar y diagnosticar el estado de la propuesta formativa, con la intención de impulsar las acciones de mejora que sean del caso. Por ejemplo, respecto de la evaluación de aprendizajes hay mucho por mejorar si se quiere trascender esquemas tradicionales en los que la calificación es sólo un dato de discriminación, de inclusión - exclusión, de formalidad educativa para establecer quiénes avanzan y quiénes no. La evaluación claramente implica calificación; más técnicamente, la construcción de un indicador. Pero el fin no es esa calificación, sino el tipo de reorientaciones que puede sufrir el proceso de formación a partir de lo que expresan los indicadores construidos. La función de la evaluación ha de ser más la de 
formar al estudiante que la de informar sobre el estudiante.

De esta manera, la evaluación, y el acto evaluativo como unidad, suponen operaciones o subprocesos que van desde el establecimiento de los objetivos o propósitos, la delimitación y caracterización del objeto de evaluación, la definición (selección, elaboración) y aplicación de los instrumentos para la recogida de la información, el procesamiento y análisis de dicha información, su interpretación y expresión en un juicio evaluativo, la retroinformación, y toma de decisiones derivadas de él, su aplicación y valoración de resultados. Para recomenzar en un ciclo ascendente, progresivo, que permite, en su dinámica, imprimir el auténtico significado de esta actividad. La evaluación supone, además, la propia valoración de ella (González, 2001, p.88).

No podríamos terminar este apartado sin una referencia a la investigación como actividad central del proceso formativo, pero también como actividad necesaria para mantener vigentes las propuestas curriculares. La investigación como criterio rector de un currículo potencia el conocimiento científico, que, como bien señala Cruz Kronfly, se constituye en:

una forma de ver y entender el mundo que se separa del sentido común y de las ideologías, que rompe con ese sustrato que Platón denominaba «opinión» y que apunta sin concesiones, a desvelar críticamente las «apariencias» y los «imaginarios» que «encubren» lo real. El conocimiento científico que en su forma moderna conduce a la ciencia, resulta impensable sin el concurso de la investigación (2007, p.204).

\section{Consideraciones finales}

El PEP, como documento soporte de las tentativas de un programa en cuanto a formación, ha de ser la guía de las acciones institucionales, colectivas e individuales en el seno de la Universidad. Los programas de Contaduría Pública encuentran como carta de presentación dicho proyecto educativo, documento que a su vez permite construir un juicio sobre los ideales de formación y su contraste con lo que ocurre en la cotidianidad de la vida académica.
Hemos sentado una posición crítica al proponer nuestra lectura particular de los componentes de dicho documento y de aquellas orientaciones que creemos son pertinentes para una educación contable comprometida con los problemas de nuestro tiempo. En particular, creemos que la problematización del contexto, la comprensión del funcionamiento del mundo de las organizaciones, la identificación de los impactos que propone el actual circuito de la globalización y sus estratagemas geopolíticas, la concepción del tipo de sujeto epistémico, ético, estético y político que requiere una sociedad justa, incluyente y fraterna capaz de contraponerse a los valores de la actual racionalidad económica instrumental y perversa, hacen parte de la ubicación de un propósito de formación para la Contaduría Pública. También hemos advertido que esos ideales formativos se hacen coherentes con una concepción de la Contabilidad como complejidad, como campo del conocimiento con profundas consecuencias simbólicas y prácticas en la definición del comportamiento presente y futuro de las organizaciones e instituciones del mundo del trabajo; una concepción de la Contabilidad con poder constitutivo, y por ello, con potencia para el mejoramiento de las relaciones del actual sistema mundo.

El sentido de un PEP puede ser resumido como la acción de agrupar, aglutinar articuladamente un conjunto de relaciones, de prescripciones en el campo de la formación de la subjetividad, de la concepción de la Contabilidad y de los atributos derivados de la teoría educativa. No hablamos de cualquier proyecto educativo, sino de aquél que se comprometa con la dignificación de la profesión contable, del sujeto contador público y de la sociedad local y global en la que vive. Es tarea de los programas de Contaduría Pública renovar su compromiso con una formación más dignificante de la condición humana y poblar de capital simbólico a una profesión para el interés público y la construcción de espacios de confianza.

Pensar hoy los PEP implica aceptar que el plano curricular (dimensión estratégica de la política académica) requiere de reflexiones pedagógicas que potencien el pensamiento de la Contabilidad. El PEP debe guiar el diseño de los programas, pero para ello es necesario que las comunidades académicas asuman con rigor la tarea de concretar los mínimos que han sido deliberados y documentados. 
Algunas investigaciones quedarían abiertas para complementar esta reflexión sobre el sentido de un proyecto educativo en Contaduría Pública, por ejemplo, la comparación de proyectos educativos y sus estrategias de materialización, la definición de condiciones de gestión de un PEP en una lógica similar a los presupuestos aquí consignados, las relaciones entre PEP y formación de maestría y doctorado, entre otras.

\section{Referencias}

Álvarez, H. y Gómez M. (2008). Adopción de la normativa contable internacional: ies el camino correcto? Análisis del proyecto de Ley 165 del 2007. Revista Internacional Legis de Contabilidad y \& Auditoría, 35, 39-71.

Archel, P., Husillos, J., Gil, J. y Rojas W. (2009). Irrupciones significativas para pensar la contabilidad. Santiago de Cali: Universidad del Valle.

Barragán, D. (2008). Currículum e interacciones en el aula. La formación en Contaduría Pública. En: Perspectivas críticas de la contabilidad. VII simposio Nacional de Investigación Contable y Docencia. Pp. $159-172$.

Cardona, J. y Zapata, M. (2006). Educación contable: antecedentes y prospectiva. Colombia: Universidad de Antioquia - ASFACOP.

Cruz, F. (2007). La Derrota de la Luz. Colombia: Programa Editorial de la Universidad del Valle.

Chua, W. (1986/2009). Desarrollos radicales en el pensamiento contable. En: Gómez, M y Ospina, C. (Ed.) (2009). Avances Interdisciplinarios para una Comprensión Crítica de la Contabilidad. Textos Paradigmáticos de las Corrientes Heterodoxas. Colombia: Escuela de Administración y Contaduría Pública, Universidad Nacional de Colombia y Departamento de Ciencias Contables, Universidad de Antioquia.

Díaz, A. y Quiroz, R. (2001). Corrientes pedagógicas, modelos pedagógicos y enfoques curriculares. Relación sistemática entre ellos. Revista avanzada, 10, 116 - 129.

Diccionario de la Real Academia de La lengua Española, Vigésima segunda edición.
Fals Borda, O. (2009). Una sociología sentipensante para América Latina. Colombia: Siglo del Hombre Editores - CLACSO.

Gómez, M y Ospina, C. (Ed.) (2009). Avances Interdisciplinarios para una Comprensión Crítica de la Contabilidad. Textos Paradigmáticos de las Corrientes Heterodoxas. Colombia: Escuela de Administración y Contaduría Pública, Universidad Nacional de Colombia y Departamento de Ciencias Contables, Universidad de Antioquia.

González, M. (2001). La evaluación del aprendizaje: Tendencias y reflexión crítica. Revista Cubana de Educación Media Superior 15 (1), 85-96.

Gracia, E. (2006). Sobre las prácticas de gestión en la Universidad. Lumina 7, 110-128.

Jaramillo, R. (1998). Colombia: la modernidad postergada. Bogotá: Temis.

Larrinaga, C. (1999). Perspectivas alternativas de investigación en contabilidad: una revisión. Revista de contabilidad, 3 (2), 103-132.

Larrinaga, C. y Carrasco, F. (1996). El poder constitutivo de la contabilidad: consideraciones sobre la cuestión medioambiental. En: Ensayos sobre contabilidad y economía: en homenaje al profesor Ángel Sáenz Torrecilla, Tomo II, Págs. 65-84.

Lyotard, J. (2008). La Posmodernidad. España: Gedisa.

Mattessich, R. (2002). Contabilidad y métodos analíticos: medición y proyección del ingreso y la riqueza en la microeconomía y en la macroeconomía. Buenos Aires: La Ley.

Miller, P. y O'Leary, T. (1987/2009). La contabilidad y la construcción de la persona gobernable. En: Gómez, M. y Ospina, C. (Ed.) (2009). Avances Interdisciplinarios para una Comprensión Crítica de la Contabilidad. Textos Paradigmáticos de las Corrientes Heterodoxas. Colombia: Escuela de Administración y Contaduría Pública, Universidad Nacional de Colombia y Departamento de Ciencias Contables, Universidad de Antioquia. 
Nussbaum, M. (2010). Sin fines de Lucro: por qué la democracia necesita de las humanidades. Madrid: Editorial Katz.

Rojas, W. (2003). Modernidad \& Inhumanidad: 10 Inhumano en la organización y en el Trabajo. Colombia: Facultad de ciencias de la Administración de la Universidad del Valle.

Sunder, S. (1997/2005). Teoría de la contabilidad y el control. Bogotá: Universidad Nacional.

Tua, J. (1991). Desarrollo, causas y efectos multiplicadores de la investigación empírica. $L a$ Investigación Empírica en Contabilidad. La Hipótesis de Eficiencia del Mercado. España: Ministerio de Economía y Hacienda. 19-55.

Vargas, G. (2000). La educación del futuro como futuro de la educación: ensayo fenomenológico de filosofía de la educación. Pedagogía y saberes, 14, 57-66. 